\title{
Light-response curve of photosynthesis and model fitting in leaves of Mangifera indica under different soil water conditions
}

\author{
Y.L. LI* X.G. LIU*,+, K. HAO**, Q.L. YANG ${ }^{*}$, X.Q. YANG*, W.H. ZHANG*, and Y. CONG* \\ Faculty of Modern Agricultural Engineering, Kunming University of Science and Technology, 650500 Kunming, \\ Yunnan, China* \\ Faculty of Water Resources and Hydroelectric Engineering, Xi'an University of Technology, 710048 Xi'an, \\ Shanxi, China**
}

\begin{abstract}
A pot experiment was performed to study the light-response curve of photosynthesis ( $P_{\mathrm{N}}$-PAR curve) of Mangifera indica and the applicability of light-response models under different soil water conditions. The experimental data were fitted and analyzed using the rectangular hyperbola model, the nonrectangular hyperbola model, the exponential model, the modified rectangular hyperbola model, and the kinetic model. The results showed that the optimal range of relative soil water content (RSWC) for the normal photosynthesis of $M$. indica was 45.1-77.3\%. The modified rectangular hyperbola model could well fit the $P_{\mathrm{N}}$-PAR curves and photosynthetic parameters under wide range of soil water conditions (RSWC 23.3-77.3\%). The rectangular hyperbola model, the nonrectangular hyperbola model, the exponential model, and the kinetic model could only be used to fit the $P_{\mathrm{N}}$-PAR curves of $M$. indica under mild and moderate drought stress (RSWC 45.1-77.3\%).
\end{abstract}

Additional key words: field capacity; light-compensation point; light-response curve; model comparison; net photosynthetic rate.

\section{Introduction}

Photosynthesis is a biological process in which plants convert light energy into chemical energy that can be used in life processes and synthesize organic matter. In this process, the quantitative relationship between net photosynthetic rate $\left(P_{\mathrm{N}}\right)$ and photosynthetically active radiation (PAR) is the basis for revealing the response of the photosynthetic physiological process of plant to the environment (Govindjee and Krogmann 2004, Elfadl and Luukkanen 2006, Wang et al. 2017). The measurement and simulation of light-response curve of photosynthesis ( $P_{\mathrm{N}}$-PAR curve) is one of the important methods in studying the photosynthetic physiological ecology of plants. The main physiological parameters, such as maximum net photosynthetic rate $\left(P_{\mathrm{Nmax}}\right)$, apparent quantum yield (AQY), light-saturation point (LSP), light-compensation point $(\mathrm{LCP})$, and dark respiration rate $\left(R_{\mathrm{D}}\right)$, can be obtained from the curve, which are helpful to determine the operation state of plant photosynthetic apparatus, photosynthetic capacity, and photosynthetic efficiency as well as an environmental changes influencing them (Sharp et al. 1984, Ye and Yu 2008a, Xia et al. 2014). Soil water content (SWC) is the major environmental factor affecting plant growth and metabolism, and drought stress often occurs and restricts plant growth and development, especially photosynthesis (Sofo et al. 2009, Ruzana Adibah and Ainuddin 2011, Wang et al. 2017). Therefore, it is important to study $P_{\mathrm{N}}$-PAR curve under different soil water conditions to reveal quantitative relationship between photosynthetic characteristics and SWC.

Light-response model is essential for study of the $P_{\mathrm{N}}$-PAR curve of plants. Many light-response models of photosynthesis have been constructed by experts (Bassman and Zwier 1991, Thornley 1998, Lewis et al. 1999), among which the rectangular hyperbola model, the nonrectangular hyperbola model, and the exponential model have been commonly used (Lang et al. 2013, Lobo et al. 2013, Xia et al. 2014, Wang et al. 2017, Duan et al. 2018). However, some researches have shown that there was deficiency in practical applications of the three models. The fitted values of photosynthetic parameters

Received 4 January 2019, accepted 7 May 2019.

${ }^{+}$Corresponding author; e-mail: liuxiaogangjy@126.com

Abbreviations: AQY - apparent quantum yield; FC - field capacity; GWC - gravitational water content; LCP - light-compensation point; LSP - light-saturation point; $P_{\mathrm{N}}-$ net photosynthetic rate; $P_{\mathrm{Nmax}}-$ maximum net photosynthetic rate; $P_{\mathrm{N}}$-PAR curve - lightresponse curve of photosynthesis; $R^{2}$ - determination coefficient; $R_{\mathrm{D}}$ - dark respiration rate; RSWC - relative soil water content; SWC - soil water content.

Acknowledgements: This study was supported by the National Natural Science Foundation of China (No. 51769010, No. 51469010), the Innovative Training Program for College Students (No. 201810674023), and Analysis and Testing Foundation of KUST (No. 2018T20090043) 
were significantly different from the measured values (Ye 2007, Chen et al. 2011), and it was difficult to process experimental data under photoinhibition conditions, especially, the three models were only suitable for fitting the $P_{\mathrm{N}}$-PAR curve and photosynthetic parameters under the normal soil water conditions (Lang et al. 2013, Xia et al. 2014, Wang et al. 2017). In recent years, Ye et al. (2007, $2008 \mathrm{a}, \mathrm{b})$ constructed a new light-response model - the modified rectangular hyperbola model, which was based on the rectangular hyperbola model. This new model may overcome the limitation of the traditional model and could accurately fit $P_{\mathrm{N}}$-PAR curve and photosynthetic parameters under various environmental conditions (Ye 2007, Ye and Yu 2008b). Up to now, the modified rectangular hyperbola model has been applied to simulate the $P_{\mathrm{N}}$-PAR curves of spring wheat, Nicotiana tabacum L., Prunus sibirica L., Pinus tabulaeformis, Hippophae rhamnoides L., Ziziphus jujuba var. spinosus, and Populus euphratica under different soil water conditions (Chen et al. 2011, Lang et al. 2013, Xia et al. 2014, Wang et al. 2017, Duan et al. 2018) and has achieved good results.

Mangifera indica, an evergreen tree belonging to the family of Anacardiaceae, is a typical perennial tropical fruit tree and enjoys the reputation of 'the king of tropical fruits' with remarkable economic benefits (Zang et al. 2009, Sarker et al. 2016). M. indica is mostly planted in mountain or hilly areas, and its growth and development is extremely vulnerable to drought stress during the dry season (Yao et al. 2006, Zang et al. 2009, Lu et al. 2012, Levin et al. 2018). At present, many studies have been done to investigate the photosynthetic characteristics (Yao et al. 2006, Elsheery and Cao 2008, Lu et al. 2012, dos Santos et al. 2013, 2014a, 2015), leaf physiological activity (Jia et al. 2000, Zaharah and Razi 2009, dos Santos et al. 2015), growth (Zaharah and Razi 2009), root distribution (dos Santos et al. 2014b), fruit yield (dos Santos et al. 2014a,b; 2015), and floral initiation (Bally et al. 2000, Chen et al. 2000, Lu and Chacko 2000) of M. indica under different soil water conditions or irrigation levels. In most studies, only a few water levels have been considered. It is necessary to obtain a sufficient amount of experimental data under multilevel SWC to accurately characterize the relationship between the photosynthesis and SWC. There was little information on the fitting and comparison of the $P_{\mathrm{N}}$-PAR curve of $M$. indica under drought stress in previous studies. Therefore, we used two-year-old $M$. indica seedlings to measure $P_{\mathrm{N}^{-}}$ PAR curves under different soil water conditions, fitted $P_{\mathrm{N}}$-PAR curves and main photosynthetic parameters by the rectangular hyperbola model, the nonrectangular hyperbola model, the exponential model, the modified rectangular hyperbola model, and the kinetic model. The aims of this study were to explore the relationship between photosynthesis and SWC, clarify the adaptability of these light-response models, and gain further understanding of the photosynthetic physiological characteristics of $M$. indica under different soil water conditions. The results could provide theoretical basis and practical guidance for soil water management of $M$. indica in actual production and cultivation.

\section{Materials and methods}

Experimental materials: Pot experiment was conducted in the research greenhouse of Faculty of Modern Agricultural Engineering, Kunming University of Science and Technology in Kunming, Yunnan, China $\left(24^{\circ} 9^{\prime} \mathrm{N}\right.$, $102^{\circ} 79^{\prime} \mathrm{E}$; 1,978.9 $\mathrm{m}$ a.s.1.) from May to August 2018 . The greenhouse was oriented from north to south, and the light intensity was approximately $90 \%$ of the natural light. The length, span, and ridge height were 100, 21, and $3 \mathrm{~m}$, respectively. The temperature was $20-35^{\circ} \mathrm{C}$, the air humidity was $45-70 \%$, and the $\mathrm{CO}_{2}$ concentration

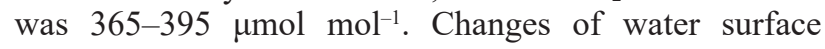
evaporation in greenhouse during the experimental period were shown in Fig. 1. Two-year-old Mangifera indica. cv. Guifei seedlings were selected for the experiment. In May 2018 , ten healthy seedlings with relatively uniform plant height and basal diameter were transplanted into white plastic buckets ( $44 \mathrm{~cm}$ in diameter at the top edge, $35 \mathrm{~cm}$ in diameter at the bottom, and $53 \mathrm{~cm}$ in depth). Six holes were uniformly punched at the bottom of bucket to provide better aeration. After $60 \mathrm{~d}$ for nursery, five seedlings of similar growth were selected for the measurement. The average plant height was $76.8 \mathrm{~cm}$ and the average basal diameter was $10.25 \mathrm{~mm}$. The experimental soil was red loam, which was air dried and sieved (in a 2-mm sieve). The contents of organic matter, total $\mathrm{N}$, total $\mathrm{P}$, and total $\mathrm{K}$ in soil were $5.05,0.87,0.68$, and $13.9 \mathrm{~g} \mathrm{~kg}^{-1}$, respectively. Soil of $72 \mathrm{~kg}$ was added to each bucket; the soil was in average bulk density of $1.20 \mathrm{~g} \mathrm{~cm}^{-3}$ and average field capacity (FC) of $24.4 \%$.

Acquisition of soil water gradient: Natural drought stress was applied on 10 July, 2018. Three days before the measurement of $P_{\mathrm{N}}$-PAR curve, five experimental seedlings were provided by normal water supply (SWC reached FC of $85 \%$ ), then the soil was naturally dried and no water was added. In order to obtain sufficient soil water gradients, the soil surface was covered with pine needles to slow down water evaporation. As soil water decreased gradually by evapotranspiration, the gravitational water content (GWC) and $P_{\mathrm{N}}$-PAR curves were measured every three days, until the seedlings withered. GWC was measured by the convective oven-drying method, and the relative soil water content (RSWC) was the ratio of GWC to FC. All GWC and RSWC obtained during the experiment are shown in the text table:

\begin{tabular}{lll}
\hline Drought stress type & GWC [\%] & RSWC [\%] \\
\hline Mild drought stress & $18.88 \pm 2.77$ & $77.30 \pm 4.69$ \\
& $15.91 \pm 1.40$ & $65.14 \pm 5.04$ \\
Moderate drought stress & $13.38 \pm 1.05$ & $54.77 \pm 5.10$ \\
& $11.01 \pm 0.92$ & $45.06 \pm 3.88$ \\
& $8.99 \pm 1.81$ & $36.81 \pm 4.50$ \\
Severe drought stress & $6.89 \pm 1.66$ & $28.19 \pm 3.14$ \\
& $5.68 \pm 0.93$ & $23.25 \pm 4.14$ \\
\hline
\end{tabular}


$\boldsymbol{P}_{\mathrm{N}}$-PAR curves were measured using the portable photosynthetic system (LI-COR 6400, LI-COR Inc., Lincoln, NE, USA) under different soil water conditions. After each SWC measurement, three healthy and mature leaves from the center of each seedling crown were selected and marked as fixed measured leaves. $P_{\mathrm{N}}$-PAR curves were measured three times for each marked leaf, so that nine measurements were made for each seedling and 45 replications for each soil water gradient. The average value of 45 replications was taken for analysis. Measurements were made between $8: 30-11: 30 \mathrm{~h}$ on a sunny day under each soil water gradient. Before each measurement, the measured leaves were induced about 20-30 min at light intensity of 1,200 umol(photon) $\mathrm{m}^{-2} \mathrm{~s}^{-1}$. During the measurement, the flow rate of air in the measuring chamber was about $500 \mu \mathrm{mol}$ $\mathrm{s}^{-2}$, the atmospheric $\mathrm{CO}_{2}$ concentration was maintained at $375 \pm 5 \mu \mathrm{mol} \mathrm{mol}{ }^{-1}$, the temperature of the leaf chamber was $25 \pm 1{ }^{\circ} \mathrm{C}$, and the relative humidity was $50 \pm 5 \%$. For every measurement, PAR was set at 2,000; 1,800; 1,$500 ; 1,200 ; 1,000 ; 800,600,400,200,150,100,50$, 20 , and $0 \mu \mathrm{mol}$ (photon) $\mathrm{m}^{-2} \mathrm{~s}^{-1}$ by artificial $\mathrm{Li}-6400-02 B$ LED radiation source to measure $P_{\mathrm{N}}$ under different light intensities. For each PAR, the measurement time was controlled to $180 \mathrm{~s}$ and the photosynthetic parameters such as $P_{\mathrm{N}}$ were recorded automatically by the instrument.

$P_{\mathrm{N}}$-PAR curves were drawn according to the measured data under different soil water conditions. $P_{\mathrm{Nmax}}, \mathrm{LCP}$, and $R_{\mathrm{D}}$ were estimated according to the trend of measured curve, and AQY was obtained by using the linear regression method of the $P_{\mathrm{N}}$-PAR curve under weak light conditions $\left[\mathrm{PAR} \leq 200 \mu \mathrm{mol}\right.$ (photon) $\mathrm{m}^{-2} \mathrm{~s}^{-1}$. The estimated photosynthetic parameters were considered the measured values and they were used to compare with the fitted values of following models.

\section{Five light-response models}

The rectangular hyperbola model (Lewis et al. 1999) was expressed as follows:

$P_{\mathrm{N}}=\frac{\alpha \times I \times P_{\mathrm{N} \max }}{\alpha \times I+P_{\mathrm{N} \max }}-R_{\mathrm{D}}$

where $P_{\mathrm{N}}$ is the net photosynthetic rate, $\alpha$ is the apparent quantum yield, $P_{\text {Nmax }}$ is the maximum net photosynthetic rate, $R_{\mathrm{D}}$ is the dark respiration rate, and $I$ is PAR.

If the measured data can be fitted well by the above model, LCP can be calculated by (Lang et al. 2013):

$I_{\mathrm{C}}=\frac{R_{D} \times P_{\mathrm{N} \max }}{\alpha \times\left(P_{\mathrm{N} \text { max }}-R_{\mathrm{D}}\right)}$

where $I_{\mathrm{C}}$ is LCP.

The nonrectangular hyperbola model (Thornley et al. 1998) was expressed as follows:

$P_{\mathrm{N}}=\frac{\alpha \times I+P_{\mathrm{N} \max }-\sqrt{\left(\alpha \times I+P_{\mathrm{N} \max }\right)^{2}-4 \times \theta \times \alpha \times I \times P_{\mathrm{N} \max }}}{2 \times \theta}-R_{\mathrm{D}}$ where $\theta(0<\theta \leq 1)$ is the curvilinear angle of the nonrectangular hyperbola, and the other parameters are as described above.

If the measured data can be fitted well by the above model, LCP can be calculated by (Lang et al. 2013):

$$
I_{\mathrm{C}}=\frac{R_{\mathrm{D}} \times P_{\mathrm{N} \text { max }}-\theta \times R_{\mathrm{D}}^{2}}{\alpha \times\left(P_{\mathrm{N} \text { max }}-R_{\mathrm{D}}\right)}
$$

Exponential model: There are many different expressions for the exponential models. This research selected the exponential model proposed by Bassman and Zwier (1991):

$$
P_{\mathrm{N}}=P_{\mathrm{N} \text { max }} \times\left(1-e^{-(\alpha \times I) / P_{\mathrm{N} \text { max }}}\right)-R_{\mathrm{D}}
$$

The parameters are as described above.

If the measured data can be fitted well by the above model, LCP can be calculated by (Wang et al. 2017):

$I_{\mathrm{C}}=\frac{-P_{\mathrm{N} \max }}{\alpha} \times \ln \left(\frac{P_{\mathrm{N} \max }-R_{\mathrm{D}}}{P_{\mathrm{N} \max }}\right)$

The modified rectangular hyperbola model (Ye 2007, Ye and Yu 2008a,b) was expressed as follows:

$$
\begin{gathered}
P_{\mathrm{N}}=\alpha \times \frac{1-\beta \times I}{1+\gamma \times I} \times I-R_{\mathrm{D}} \\
P_{\mathrm{N} \text { max }}=\alpha \times\left(\frac{\sqrt{\beta+\gamma}-\sqrt{\beta}}{\gamma}\right)^{2}-R_{\mathrm{D}} \\
I_{\mathrm{C}}=\frac{\alpha-\gamma \times R_{\mathrm{D}}-\sqrt{\left(\gamma \times R_{\mathrm{D}}-\alpha\right)^{2}-4 \times \alpha \times \beta \times R_{\mathrm{D}}}}{2 \times \alpha \times \beta}
\end{gathered}
$$

where $\beta$ and $\gamma$ are modified coefficients that are independent of $I$ and the other parameters are as described above.

The kinetic model: The light-response process of plant photosynthesis conformed to the Michaelis-Menten equation of enzymatic kinetics. The kinetic model (Broadley et al. 2001) was expressed as follows:

$P_{\mathrm{N}}=\frac{P_{\mathrm{N} \max } \times\left(I-I_{\mathrm{C}}\right)}{K_{\mathrm{m}}+I-I_{\mathrm{C}}}$

where $K_{\mathrm{m}}$ is the value of $I$ when $P_{\mathrm{N}}$ is half of $P_{\mathrm{Nmax}}, I_{\mathrm{C}}$ is the value of $I$ at which $P_{\mathrm{N}}$ reaches 0 (LCP), and the other parameters are as described above.

Statistical analysis: $P_{\mathrm{N}}-\mathrm{PAR}$ curves and photosynthetic parameters were analyzed statistically and fitted nonlinearly by Statistical Package for the Social Sciences 19.0 software for Windows. The experimental data 


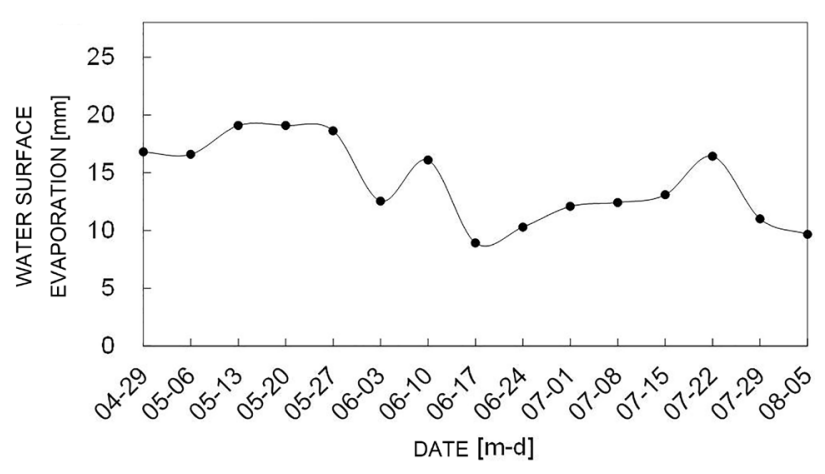

Fig. 1. Changes of water surface evaporation in the greenhouse during the experimental period from May to August 2018.

processing and drawing were performed by Microsoft Excel 2010. The initial values used in the models were: the rectangular hyperbola model: $\alpha=0.05, P_{\mathrm{Nmax}}=20 \mu \mathrm{mol}$ $\mathrm{m}^{-2} \mathrm{~s}^{-1}, R_{\mathrm{D}}=2 \mu \mathrm{mol} \mathrm{m} \mathrm{m}^{-2} \mathrm{~s}^{-1}$; the nonrectangular hyperbola model: $\alpha=0.05, P_{\mathrm{N} \max }=20 \mu \mathrm{mol} \mathrm{m} \mathrm{m}^{-2} \mathrm{~s}^{-1}, \theta=0.5, R_{\mathrm{D}}=$ $2 \mu \mathrm{mol} \mathrm{m} \mathrm{m}^{-2} \mathrm{~s}^{-1}$; the exponential model: $\alpha=0.05, P_{\mathrm{Nmax}}=$ $20 \mu \mathrm{mol} \mathrm{m}^{-2} \mathrm{~s}^{-1}, R_{\mathrm{D}}=2 \mu \mathrm{mol} \mathrm{m}^{-2} \mathrm{~s}^{-1}$; the modified rectangular hyperbola model: $\alpha=0.01, \beta=0.0001, \gamma=0.001$, $R_{\mathrm{D}}=2 \mu \mathrm{mol} \mathrm{m}{ }^{-2} \mathrm{~s}^{-1}$; the kinetic model: $P_{\mathrm{Nmax}}=20 \mu \mathrm{mol} \mathrm{m}{ }^{-2}$ $\mathrm{s}^{-1}, I_{\mathrm{C}}=40 \mu \mathrm{mol} \mathrm{m} \mathrm{m}^{-2} \mathrm{~s}^{-1}, K_{\mathrm{m}}=300 \mu \mathrm{mol} \mathrm{m}{ }^{-2} \mathrm{~s}^{-1}$.

\section{Results}

The $\boldsymbol{P}_{\mathrm{N}}$-PAR curves under different soil water conditions: The response of $P_{\mathrm{N}}$ to PAR was significantly diverse under different soil water conditions (Fig. 2). The $P_{\mathrm{N}}$-PAR curves could be divided into three stages, among which the first and second stage showed a similar trend of the response regardless of RSWC. In the first stage, where PAR $<200 \mu \mathrm{mol}$ (photon) $\mathrm{m}^{-2} \mathrm{~s}^{-1}, P_{\mathrm{N}}$ increased linearly as PAR increased. With the further increase of PAR, the curves entered the second stage, $P_{\mathrm{N}}$ increased curvilinearly to saturation, and $P_{\mathrm{N} \max }$ appeared. The $P_{\mathrm{N}}$-PAR curves in the third stage were significantly different under different soil water conditions. Under mild and moderate drought stress,

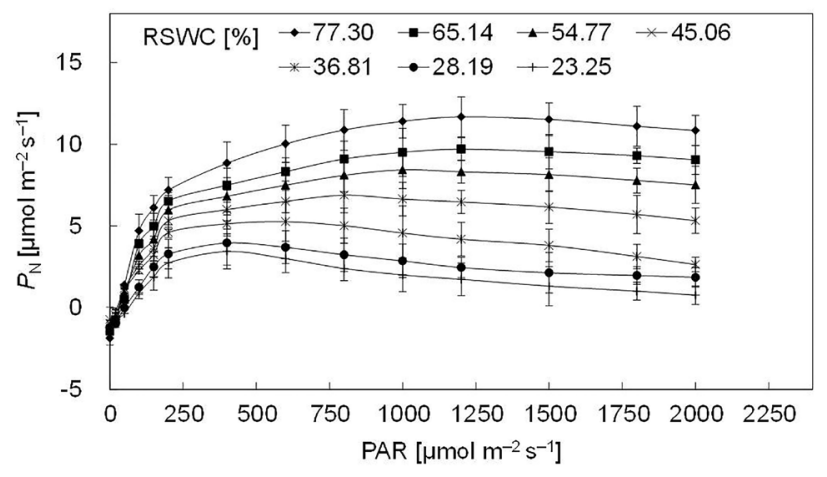

Fig. 2. The $P_{\mathrm{N}}$-PAR curves of Mangifera indica under different soil water conditions. $P_{\mathrm{N}}-$ net photosynthetic rate; PAR photosynthetically active radiation; RSWC - relative soil water content. Bars indicate $\pm \mathrm{SE}$ of the mean, $n=45$.
$P_{\mathrm{N}}$ reached saturation at PAR of $1,200 \mu \mathrm{mol}$ (photon) $\mathrm{m}^{-2} \mathrm{~s}^{-1}$, then $P_{\mathrm{N}}$ decreased slowly and maintained at a higher level without obvious photoinhibition. Under severe drought stress, $P_{\mathrm{N}}$ reached saturation at low PAR. When PAR $>800$ $\mu$ mol(photon) $\mathrm{m}^{-2} \mathrm{~s}^{-1}, P_{\mathrm{N}}$ decreased significantly with the continuous increase of PAR and obvious photoinhibition was observed.

With the decrease of RSWC, $P_{\mathrm{N}}$ gradually decreased and the decreasing amplitude increased significantly under the same PAR. Compared to RSWC of $77.3 \%, P_{\mathrm{N}}$ decreased by $16.6,26.0,41.7,59.9,74.8$, and $82.3 \%$, respectively, when RSWC was $65.1,54.8,45.1,36.8,28.2$, and $23.3 \%$ at PAR of 1,000 $\mu \mathrm{mol}$ (photon) $\mathrm{m}^{-2} \mathrm{~s}^{-1}$. Relatively higher $P_{\mathrm{N}}, \mathrm{LSP}, P_{\mathrm{Nmax}}$, and less obvious photoinhibition were observed in the RSWC region of $45.1-77.3 \%$. Thus, it could be considered that $45.1-77.3 \%$ was the suitable soil water range for the photosynthesis of $M$. indica.

Fitting of the $\boldsymbol{P}_{\mathrm{N}}$-PAR curves: The fitting effects of five light-response models on $P_{\mathrm{N}}$-PAR curves were significantly different under different soil water conditions (Fig. 3). Except for the modified rectangular hyperbola model, there were significant discrepancies between the fitted and measured values of the other four models under high PAR, especially the discrepancies were more obvious under severe drought stress. In addition, $P_{\mathrm{N}}$-PAR curves that were fitted by these four models were all asymptotic curves with no extreme value under high PAR. Particularly, under severe drought stress, they could not fit well the decline process of $P_{\mathrm{N}}$. Among the all models, the rectangular hyperbola model and the nonrectangular hyperbola model had the worst fitting effects. The modified rectangular hyperbola model could well fit $P_{\mathrm{N}}$-PAR curves under each soil water conditions and the fitting effect was the best as the fitted curves were consistent with the measured curves. Furthermore, only the modified rectangular hyperbola model could fit well the curves of $P_{\mathrm{N}}$ decreasing with the increase of PAR.

Fitting analysis of the photosynthetic parameters: The fitted results showed that under mild and moderate drought stress, all five light-response models had higher determination coefficients $\left(R^{2}>0.94\right)$, and the fitting accuracy of the modified rectangular hyperbola model was the highest $\left(R^{2}>0.99\right)$. Under severe drought stress, only $R^{2}$ of the modified rectangular hyperbola model was greater than 0.9 , while $R^{2}$ of other four models ranged from 0.40-0.86 (Table 1). Therefore, the modified rectangular hyperbola model was the best way to fit $P_{\mathrm{N}}$ PAR curves.

Under mild and moderate drought stress, the fitted values of $R_{\mathrm{D}}$ by five models showed no significant differences from the measured values. The fitted $P_{\text {Nmax }}$ and LCP of the modified rectangular hyperbola model were close to the measured values. The fitted $P_{\text {Nmax }}$ of other four models were higher than the measured values, while the fitted LCP were smaller than the measured values (Table 1). Under severe drought stress, only the modified rectangular hyperbola model had better the fitting effect on the photosynthetic parameters. For the other four models, the fitted values of photosynthetic parameters deviated 


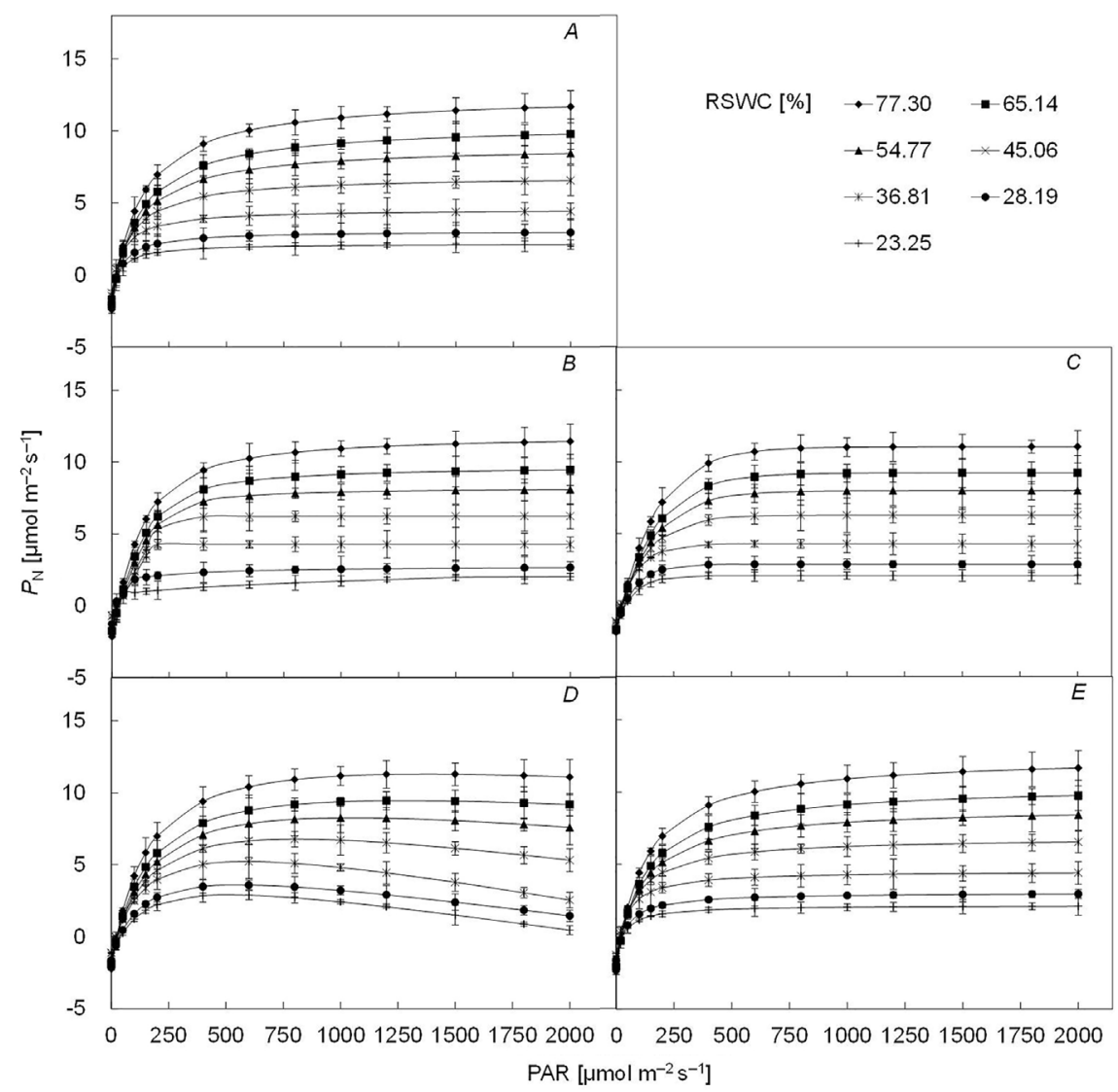

Fig. 3. Fitting of the $P_{\mathrm{N}}-\mathrm{PAR}$ curves of Mangifera indica by the rectangular hyperbola model $(A)$, the nonrectangular hyperbola model $(B)$, the exponential model $(C)$, the modified rectangular hyperbola model $(D)$, and the kinetic model $(E)$ under different soil water conditions. $P_{\mathrm{N}}-$ net photosynthetic rate; PAR - photosynthetically active radiation; RSWC - relative soil water content. Bars indicate $\pm \mathrm{SE}$ of the mean, $n=45$.

more from the measured values. By the comparison and analysis, the fitting effects of five light-response models on the photosynthetic parameters were in the descending order: the modified rectangular hyperbola model, the exponential model, the kinetic model, the nonrectangular hyperbola model, and the rectangular hyperbola model.

As shown in Table 1, AQY and $P_{\text {Nmax }}$ decreased continually with the decrease of RSWC. Under mild and moderate drought stress, $R_{\mathrm{D}}$ and LCP decreased gradually with the decrease of RSWC. However, $R_{\mathrm{D}}$ and LCP increased significantly under severe drought stress.

\section{Discussion}

Photosynthesis cannot proceed normally when soil water is seriously inadequate (Beis and Patakas 2012, Xia et al. 2014). Drought stress can lead to the decrease of $P_{\mathrm{N}}$ depending on the stress level; mild water deficit has no significant effect or can even increase $P_{\mathrm{N}}$, while severe water deficit can decrease $P_{\mathrm{N}}$ significantly (Zhang et al. 2007, Xia et al. 2011, Lang et al. 2013). Therefore, soil water is an important environmental factor that can directly regulate photosynthesis, water physiology, and metabolism of plants (Hu et al. 2004, Sofo et al. 2009, Wang et al. 2017). In this research, we found that $P_{\mathrm{N}}$ decreased significantly with the decrease of RSWC under the same PAR and the degree of photoinhibition was significantly related to RSWC in $M$. indica. High $P_{\mathrm{N}}$ was maintained and no photoinhibition occurred under mild and moderate drought stress. In contrast, obvious photoinhibition occurred and $P_{\mathrm{N}}$ decreased significantly under severe drought stress, which was n agreement with the results showing that photoinhibition can reduce photosynthetic productivity under low RSWC and high PAR (Lang et al. 2013). Previous studies have shown that water deficit is a common limiting factor in the photosynthesis and water deficit remarkably reduced $P_{\mathrm{N}}$, possibly due to the decrease of stomatal conductance, the obstruction of $\mathrm{CO}_{2}$ diffusion into leaves, or the decline of photosynthetic activity of mesophyll cells induced by drought stress (Galmés et al. 2007, Pascual et al. 2010, Chastain et al. 2014).

The fitting of light-response model is an important method to elucidate the response mechanism of photosynthesis and evaluate the photosynthetic efficiency (Wang et al. 2017). In our research, the fitting effects of five light-response models on the $P_{\mathrm{N}}$-PAR curves of $M$. indica were compared under different soil water conditions. The fitting effects of the rectangular hyperbola model, the nonrectangular hyperbola model, the exponential model, and the kinetic model on $P_{\mathrm{N}}$-PAR curves were better $\left(R^{2}>0.9\right)$ only under mild and moderate drought stress. These four models could not fit the decline process of $P_{\mathrm{N}}$-PAR curves when severe drought stress and photoinhibition occurred, which indicated that the application and fitting accuracy of above four models were largely limited under severe drought stress, because each model is an asymptotically saturating curve without a clear maximum within the range of the data (Lang et al. 2013). We also found that the fitting effect of the rectangular hyperbola model was the worst when photoinhibition occurred, which was 
Table 1. The measured apparent quantum yield (AQY), maximum net photosynthetic rate $\left(P_{\text {Nmax }}\right)$, dark respiration rate $\left(R_{\mathrm{D}}\right)$, and light-compensation point (LCP), and their fitted values using five light-response models for Mangifera indica under different relative soil water contents (RSWC). Each value is the mean of 45 replications and the determination coefficient $\left(R^{2}\right)$ is listed for each model.

\begin{tabular}{|c|c|c|c|c|c|c|c|c|}
\hline \multirow[t]{2}{*}{ Light response model } & \multirow{2}{*}{$\begin{array}{l}\text { Photosynthetic } \\
\text { parameter }\end{array}$} & \multicolumn{7}{|c|}{ RSWC [\%] } \\
\hline & & 77.30 & 65.14 & 54.77 & 45.06 & 36.81 & 28.19 & 23.25 \\
\hline \multirow[t]{4}{*}{ Measured value } & AQY & 0.047 & 0.042 & 0.038 & 0.030 & 0.027 & 0.024 & 0.020 \\
\hline & 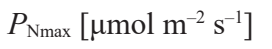 & 11.675 & 9.702 & 8.441 & 6.891 & 5.274 & 3.970 & 3.451 \\
\hline & $R_{\mathrm{D}}\left[\mu \mathrm{mol} \mathrm{m}{ }^{-2} \mathrm{~s}^{-1}\right]$ & 1.857 & 1.402 & 1.225 & 0.954 & 0.714 & 1.177 & 1.200 \\
\hline & $\mathrm{LCP}\left[\mu \mathrm{mol} \mathrm{m}{ }^{-2} \mathrm{~s}^{-1}\right]$ & 39.364 & 33.721 & 32.588 & 30.706 & 26.752 & 49.894 & 59.721 \\
\hline \multirow{5}{*}{$\begin{array}{l}\text { Rectangular hyperbola } \\
\text { model }\end{array}$} & AQY & 0.126 & 0.105 & 0.097 & 0.098 & 0.116 & 0.101 & 0.096 \\
\hline & 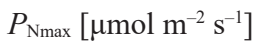 & 14.916 & 12.559 & 10.804 & 8.306 & 5.803 & 4.714 & 3.691 \\
\hline & $R_{\mathrm{D}}\left[\mu \mathrm{mol} \mathrm{m} \mathrm{m}^{-2} \mathrm{~s}^{-1}\right]$ & 2.418 & 2.070 & 1.813 & 1.422 & 1.257 & 1.650 & 1.529 \\
\hline & $\mathrm{LCP}\left[\mu \mathrm{mol} \mathrm{m}{ }^{-2} \mathrm{~s}^{-1}\right]$ & 22.903 & 23.605 & 22.460 & 17.418 & 13.748 & 25.251 & 26.949 \\
\hline & $R^{2}$ & 0.991 & 0.983 & 0.977 & 0.941 & 0.773 & 0.740 & 0.598 \\
\hline \multirow{5}{*}{$\begin{array}{l}\text { Nonrectangular } \\
\text { hyperbola model }\end{array}$} & AQY & 0.088 & 0.063 & 0.048 & 0.031 & 0.028 & 0.025 & 0.022 \\
\hline & 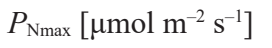 & 14.086 & 11.500 & 9.606 & 6.964 & 4.953 & 3.059 & 2.341 \\
\hline & $R_{\mathrm{D}}\left[\mu \mathrm{mol} \mathrm{m}{ }^{-2} \mathrm{~s}^{-1}\right]$ & 2.143 & 1.770 & 0.861 & 0.732 & 0.683 & 1.275 & 1.344 \\
\hline & $\mathrm{LCP}\left[\mu \mathrm{mol} \mathrm{m}{ }^{-2} \mathrm{~s}^{-1}\right]$ & 26.288 & 29.414 & 18.183 & 23.627 & 19.408 & 36.036 & 45.091 \\
\hline & $R^{2}$ & 0.993 & 0.991 & 0.991 & 0.976 & 0.863 & 0.720 & 0.409 \\
\hline \multirow[t]{5}{*}{ Exponential model } & AQY & 0.078 & 0.068 & 0.062 & 0.058 & 0.062 & 0.056 & 0.048 \\
\hline & 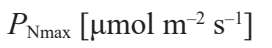 & 12.949 & 10.971 & 9.504 & 7.444 & 5.426 & 4.480 & 3.549 \\
\hline & $R_{\mathrm{D}}\left[\mu \mathrm{mol} \mathrm{m}{ }^{-2} \mathrm{~s}^{-1}\right]$ & 1.887 & 1.735 & 1.511 & 1.162 & 1.144 & 1.625 & 1.493 \\
\hline & $\mathrm{LCP}\left[\mu \mathrm{mol} \mathrm{m} \mathrm{m}^{-2} \mathrm{~s}^{-1}\right]$ & 26.147 & 27.774 & 26.542 & 21.783 & 20.722 & 36.044 & 40.363 \\
\hline & $R^{2}$ & 0.989 & 0.987 & 0.990 & 0.973 & 0.846 & 0.829 & 0.693 \\
\hline \multirow{5}{*}{$\begin{array}{l}\text { Modified rectangular } \\
\text { hyperbola model }\end{array}$} & AQY & 0.107 & 0.087 & 0.074 & 0.062 & 0.060 & 0.058 & 0.048 \\
\hline & 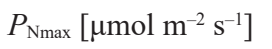 & 11.553 & 9.602 & 8.200 & 6.506 & 5.908 & 4.016 & 3.891 \\
\hline & $R_{\mathrm{D}}\left[\mu \mathrm{mol} \mathrm{m}{ }^{-2} \mathrm{~s}^{-1}\right]$ & 2.232 & 1.920 & 1.601 & 1.152 & 0.904 & 1.125 & 1.311 \\
\hline & $\mathrm{LCP}\left[\mu \mathrm{mol} \mathrm{m}{ }^{-2} \mathrm{~s}^{-1}\right]$ & 31.909 & 25.497 & 24.918 & 20.622 & 24.813 & 51.246 & 61.580 \\
\hline & $R^{2}$ & 0.994 & 0.990 & 0.992 & 0.992 & 0.982 & 0.947 & 0.933 \\
\hline \multirow[t]{5}{*}{ Kinetic model } & AQY & 0.045 & 0.038 & 0.034 & 0.028 & 0.021 & 0.017 & 0.014 \\
\hline & 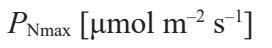 & 12.497 & 10.481 & 8.989 & 6.890 & 4.551 & 3.059 & 2.170 \\
\hline & 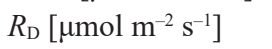 & 2.419 & 2.078 & 1.815 & 1.416 & 1.251 & 1.655 & 1.521 \\
\hline & $\mathrm{LCP}\left[\mu \mathrm{mol} \mathrm{m}{ }^{-2} \mathrm{~s}^{-1}\right]$ & 22.922 & 23.807 & 22.390 & 17.386 & 13.798 & 25.223 & 27.019 \\
\hline & $R^{2}$ & 0.991 & 0.983 & 0.977 & 0.941 & 0.773 & 0.740 & 0.598 \\
\hline
\end{tabular}

perhaps because the curved degree of $P_{\mathrm{N}}$-PAR curve was not considered in this model (Wang et al. 2017). The fitted $P_{\text {Nmax }}$ values were significantly higher than the measured values, while the fitted LCP values were lower than the measured values, thus, the photosynthetic parameters fitted by these four models deviated greatly from the measured values. The modified rectangular hyperbola model could fit well the $P_{\mathrm{N}}$-PAR curves and photosynthetic parameters of $M$. indica under mild and moderate drought stress. Meanwhile, this model can also well fit the photoinhibition response trend $\left(R^{2}>0.9\right)$ even under severe drought stress, and the fitted values of photosynthetic parameters deviated less from the measured values. This indicated that the model was insensitive to drought stress and suitable for fitting $P_{\mathrm{N}}$-PAR curves under a wide range of soil water conditions. Thus, the fitting effect of this model was better than that of the other models and it could analyze the light-response data more accurately under photoinhibition conditions. This was related to the addition of two parameters $(\beta$ and $\gamma$ ) into this model, which made the model highly advantageous in fitting the photoinhibition and lightsaturation stages under severe drought stress (Ye 2007, Ye and $\mathrm{Yu} 2008 \mathrm{~b}$ ).

The main photosynthetic parameters can be quickly estimated by light-response model. The $P_{\text {Nmax }}$ represents the maximum photosynthetic capacity of leaves and also reflects the maximum assimilation capacity under certain environmental conditions (Duan et al. 2018). The $P_{\mathrm{Nmax}}$ of $M$. indica significantly decreased with the decrease of RSWC. The results showed that the decrease of RSWC can lead to the decrease of the ability to utilize strong light, the narrowing of photosynthetically active range, and the decrease of photosynthesis and organic matter production capacity of $M$. indica. AQY is an important indicator 
of light-utilization efficiency. The common method of calculating $\mathrm{AQY}$ is to use the slope of $P_{\mathrm{N}}$-PAR curves when PAR $\leq 200 \mu \mathrm{mol}$ (photon) $\mathrm{m}^{-2} \mathrm{~s}^{-1}$. Results based on this method have shown that the range of AQY is from 0.03 to 0.05 in common plants under optimal conditions (Wang et al. 2017). In this experiment, we found that the AQY of $M$. indica decreased with the decrease of RSWC and it was in the range of 0.020-0.047 under different soil water conditions. The AQY was of 0.030-0.047 under mild and moderate drought stress and $M$. indica showed the maximum AQY of 0.047 under RSWC of $77.3 \%$. This result indicated that the light-utilization efficiency of $M$. indica was at the common level for most plants under low light and optimal soil water conditions. Ye and Yu (2008a) thought that LCP is a more reasonable indicator to evaluate the light-utilization efficiency under low light intensity, because LCP is invariant under specific environment. $R_{\mathrm{D}}$ is related to physiological activity of leaves. In our research, we found that $R_{\mathrm{D}}$ and LCP decreased gradually with the decrease of RSWC under mild and moderate drought stress. The results illustrated that the decrease of RSWC could reduce the physiological activity of leaves, but $M$. indica could resist drought stress and adapt to drought environment by increasing the ability to utilize and transform weak light and accumulating organic matter by reducing consumption of photosynthates in a certain range. $R_{\mathrm{D}}$ and LCP increased significantly under severe drought stress, indicating that the ability of $M$. indica to utilize weak light decreased under these conditions. Under severe drought stress, the photosynthetic apparatus of $M$. indica may be damaged to a certain extent and the ability to produce organic matter decreased, while the respiration consumption increased, which was not conducive to accumulation of assimilated product and ultimately led to the imbalance of nutritive material supply and demand. The LSP was not listed and compared in Table 1, because the five light-response models all function without extreme values and the LSP value cannot be accurately calculated (Lang et al. 2013, Duan et al. 2018). Relevant research has shown that it was a gradual change process for $P_{\mathrm{N}}$ from unsaturated to saturated state, so LSP should be a range, not a definite point (Duan et al. 2018).

Photosynthesis is the basis of plant growth and development and the decisive factor of plant productivity and crop yield. It is also an important reference index for plant breeding, cultivation, and the response to environmental stress (Hu et al. 2004, Xu et al. 2012, Wu et al. 2018). Light is a crucial environmental factor in the photosynthesis (Xia et al. 2011). However, when the light energy absorbed by plants exceeds their needs, the excessive excitation energy can cause photoinhibition and reduce photosynthetic efficiency. High light, together with drought stress, breaks the balance between $\mathrm{CO}_{2}$ fixation and light absorption within chloroplasts during photosynthesis, resulting in further accumulation of excessive light energy and intensifying photoinhibition (Lang et al. 2013). Moreover, serious photoinhibition can even destroy the photosynthetic apparatus (D'Ambrosio et al. 2006). In order to avoid photoinhibition, shading or irrigation are often used to ensure the normal photosynthesis and improve photosynthetic efficiency when PAR is too high in agricultural production.

In this study, $M$. indica grew poorly and the leaves withered and fell off after suffering from severe drought stress. Thus, RSWC must be maintained at more than $45 \%$ in cultivated soil to ensure the normal growth and photosynthesis of $M$. indica. In addition, transplanting of $M$. indica seedling should avoid serious arid regions or seasons as far as possible, which can reduce the influence of photoinhibition and the damage of photosynthetic apparatus in leaves to improve the survival rate to a certain extent.

Conclusion: The photosynthesis process and efficiency of $M$. indica were significantly inhibited and the degree of photoinhibition was intensified under severe drought stress (RSWC from 23.3 to $36.8 \%$ ). AQY and $P_{\text {Nmax }}$ could still maintain higher under mild and moderate drought stress (RSWC from 45.1 to $77.3 \%$ ), while decreased significantly under severe drought stress. The lightresponse model had different adaptability to the $P_{\mathrm{N}}$-PAR curves of $M$. indica under different soil water conditions. The rectangular hyperbola model, the nonrectangular hyperbola model, the exponential model, and the kinetic model were only suitable for fitting $P_{\mathrm{N}}$-PAR curves under mild and moderate drought stress, but the modified rectangular hyperbola model could perfectly fit $P_{\mathrm{N}}$-PAR curves under a wide range of soil water conditions (RSWC from $23.3 \%$ to $77.3 \%$ ) and the estimation of photosynthetic parameters was more accurate. Especially under severe drought stress, the modified rectangular hyperbola model had better applicability. It was optimal for the normal growth and photosynthesis of $M$. indica when RSWC was from 45.1 to $77.3 \%$, indicating that $M$. indica had strong drought resistance and the wide adaptation range to soil water content.

\section{References}

Bally I.S.E., Harris M., Whiley A.W.: Effect of water stress on flowering and yield of 'Kensington Pride' mango (Mangifera indica L). - Acta Hortic. 509: 277-282, 2000.

Bassman J.H., Zwier J.C.: Gas exchange characteristics of Populus trichocaarpa, Populus deltoides and Populus trichocarpa $\times$ P. deltoides clones. - Tree Physiol. 8: 145-159, 1991.

Beis A., Patakas A.: Relative contribution of photoprotection and anti-oxidative mechanisms to differential drought adaptation ability in grapevines. - Environ. Exp. Bot. 78: 173-183, 2012.

Broadley M.R., Escobar-Gutiérrez A.J., Burns A., Burns I.G.: Nitrogen-limited growth of lettuce is associated with lower stomatal conductance. - New Phytol. 152: 97-106, 2001.

Chastain D.R., Snider J.L., Collins G.D. et al.: Water deficit in field-grown Gossypium hirsutum primarily limits net photosynthesis by decreasing stomatal conductance, increasing photorespiration, and increasing the ratio of dark respiration to gross photosynthesis. - J. Plant Physiol. 171: 1576-1585, 2014.

Chen J.Z., Zhao H.Y., Ye Z.X.: [Effect of soil water stress on floral initiation and changes of endogenous hormones in mango (Mangifera indica L.).] - Chin. J. Tropical Crops 21: 74-79, 2000. [In Chinese]

Chen Z.Y., Peng Z.S., Yang J. et al.: A mathematical model for describing light-response curves in Nicotiana tabacum L. - 
Photosynthetica 49: 467-471, 2011.

D'Ambrosio N., Arena C., Virzo De Santo A.: Temperature response of photosynthesis, excitation energy dissipation and alternative electron sinks to carbon assimilation in Beta vulgaris L. - Environ. Exp. Bot. 55: 248-257, 2006.

dos Santos M.R.D., Martinez M.A., Donato S.L.R.: Gas exchanges of 'Tommy Atkins' mango trees under different irrigation treatments. - Biosci. J. 29: 1141-1153, 2013.

dos Santos M.R.D., Martinez M.A., Donato S.L.R., Coelho E.F.: 'Tommy Atkins' mango yield and photosynthesis under water deficit in semiarid region of Bahia. - Rev. Bras. Eng. Agr. Amb. 18: 899-907, 2014a.

dos Santos M.R.D., Martinez M.A., Donato S.L.R., Coelho E.F.: Fruit yield and root system distribution of 'Tommy Atkins' mango under different irrigation regimes. - Rev. Bras. Eng. Agr. Amb. 18: 362-369, 2014b.

dos Santos M.R.D., Neves B.R., da Silva B.L., Donato S.L.R.: Yield, water use efficiency and physiological characteristic of "Tommy Atkins" mango under partial rootzone drying irrigation system. - J. Water Res. Prot. 7: 1029-1037, 2015.

Duan M., Yang W.C., Mao X.M.: [Effects of water deficit on photosynthetic characteristics of spring wheat under plastic mulching and comparison of light response curve models.] Trans. CSAM 49: 219-227, 2018. [In Chinese]

Elfadl M.A, Luukkanen O.: Field studies on the ecological strategies of Prosopis juliflora in a dryland ecosystem: 1. A leaf gas exchange approach. - J. Arid Environ. 66: 1-15, 2006.

Elsheery N.I., Cao K.F.: Gas exchange, chlorophyll fluorescence, and osmotic adjustment in two mango cultivars under drought stress. - Acta Physiol. Plant. 30: 769-777, 2008.

Galmés J., Abadía A., Medrano H., Flexas J.: Photosynthesis and photoprotection responses to water stress in the wild-extinct plant Lysimachia minoricensis. - Environ. Exp. Bot. 60: 308317, 2007.

Govindjee, Krogmann D.: Discoveries in oxygenic photosynthesis (1727-2003): A perspective. - Photosynth. Res. 80: 15-57, 2004.

Hu J.C., Cao W.X., Zhang J.B.: Quantifying responses of winter wheat physiological processes to soil water stress for use in growth simulation modeling. - Pedosphere 14: 509-518, 2004.

Jia H.S., Cai S.Y., Li D.Q. et al.: [Effect on photosynthesis of mango seedlings treated with calcium under soil drying stress.] - J. Fruit Sci. 17: 52-56, 2000. [In Chinese]

Lang Y., Wang M., Zhang G.C., Zhao Q.K.: Experimental and simulated light responses of photosynthesis in leaves of three species under different soil water conditions. - Photosynthetica 51: 370-378, 2013.

Levin A.G., Peres M., Noy M. et al.: The response of field-grown mango (cv. Keitt) trees to regulated deficit irrigation at three phenological stages. - Irrigation Sci. 36: 25-35, 2018.

Lewis J.D., Olszyk D., Tingey D.T.: Seasonal patterns of photosynthetic light response in Douglas-fir seedlings subjected to elevated atmospheric $\mathrm{CO}_{2}$ and temperature. Tree Physiol. 19: 243-252, 1999.

Lobo F.D.A., de Barros M.P., Dalmagro H.J. et al.: Fitting net photosynthetic light-response curves with Microsoft Excel - a critical look at the models. - Photosynthetica 51: 445-456, 2013.

Lu P., Chacko E.K.: Effect of water stress on mango flowering in low latitude tropics of northern Australia. - Acta Hortic. 509: 283-290, 2000.

Lu P., Chacko E.K., Bithell S.L. et al.: Photosynthesis and stomatal conductance of five mango cultivars in the seasonally wet-dry tropics of northern Australia. - Sci. Hortic.-Amsterdam 138: 108-119, 2012.

Pascual I., Azcona I., Morales F. et al.: Photosynthetic response of pepper plants to wilt induced by Verticillium dahliae and soil water deficit. - J. Plant Physiol. 167: 701-708, 2010.

Ruzana Adibah M.S., Ainuddin A.N.: Epiphytic plants responses to light and water stress. - Asian J. Plant Sci. 10: 97-107, 2011.

Sarker B.C., Rahim M.A., Archbold D.D.: Combined effects of fertilizer, irrigation, and paclobutrazol on yield and fruit quality of mango. - Horticulturae 2: 14, 2016.

Sharp R.E., Matthews M.A., Boyer J.S.: Kok effect and the quantum yield of photosynthesis. - Plant Physiol. 75: 95-101, 1984.

Sofo A., Dichio B., Montanaro G., Xiloyannis C.: Photosynthetic performance and light response of two olive cultivars under different water and light regimes. - Photosynthetica 47: 602608, 2009.

Thornley J.H.M.: Dynamic model of leaf photosynthesis with acclimation to light and nitrogen. - Ann. Bot. 81: 421-430, 1998.

Wang H.Z., Han L., Xu Y.L. et al.: [Simulated photosynthetic responses of Populus euphratica during drought stress using light-response models.] - Acta Ecol. Sin. 37: 2315-2324, 2017. [In Chinese]

Wu X.H., Wang W., Xie X.L. et al.: Photosynthetic and yield responses of rice (Oryza sativa L.) to different water management strategies in subtropical China. - Photosynthetica 56: 1031-1038, 2018.

Xia J.B., Zhang G.C., Wang R.R., Zhang S.Y.: Effect of soil water availability on photosynthesis in Ziziphus jujube var. spinosus in a sand habitat formed from seashells: comparison of four models. - Photosynthetica 52: 253-261, 2014.

Xia J.B., Zhang S.Y., Zhang G.C. et al.: Critical responses of photosynthetic efficiency in Campsis radicans (L.) Seem to soil water and light intensities. - Afr. J. Biotechnol. 10: 17748-17754, 2011.

Xu J.Z., Peng S.Z., Wei Z. et al.: [Characteristics of rice leaf photosynthetic light response curve with different water and nitrogen regulation.] - Trans. CSAE 28: 72-76, 2012. [In Chinese]

Yao Q.S., Lei X.T., Wang Y.C. et al.: [Effects of different water moisture on photosynthesis, transpiration and stoma conductance of potted mango seedlings.] - J. Fruit Sci. 23: 223-226, 2006. [In Chinese]

Ye Z.P.: A new model for relationship between irradiance and the rate of photosynthesis in Oryza sativa. - Photosynthetica 45: 637-640, 2007.

Ye Z.P., Yu Q.: [Comparison of new and several classical models of photosynthesis in response to irradiance.] - Chin. J. Plant Ecol. 32: 1356-1361, 2008a. [In Chinese]

Ye Z.P., Yu Q.: A coupled model of stomatal conductance and photosynthesis for winter wheat. - Photosynthetica 46: 637 640, 2008b.

Zaharah S.S., Razi I.M.: Growth, stomata aperture, biochemical changes and branch anatomy in mango (Mangifera indica) cv. Chokanan in response to root restriction and water stress. Sci. Hortic.-Amsterdam 123: 58-67, 2009.

Zang X.P., Ma W.H., Zhang C.L.: [Primary research on the effect of drip fertilization of mango.] - Guangdong Agric. Sci. 3: 75-77, 2009. [In Chinese]

Zhang S.Y., Xia J.B., Zhou Z.F., Zhang G.C.: Photosynthesis responses to various soil moisture in leaves of Wisteria sinensis. - J. Forestry Res. 18: 217-220, 2007.

(C) The authors. This is an open access article distributed under the terms of the Creative Commons BY-NC-ND Licence. 